\title{
PULSED VACUUM OSMOTIC DEHYDRATION ON PHYSIOLOGICAL COMPOUND ENRICHMENT OF MODEL FOOD
}

\author{
KULAB SITTISUANJIK ${ }^{1}$, PHEERAYA CHOTTANOM*1, ANUCHITA MOONGNGARM ${ }^{1}$ AND \\ SIRIRAT DEESEENTHUM ${ }^{2}$
}

${ }^{1}$ Department of Food Technology and Nutrition, ${ }^{2}$ Department of Biotechnology, Faculty of Technology, Mahasarakham University, Khamriang, Kantarawichai, Mahasarakham 44150 Thailand.

*Corresponding author: pheeraya.c@msu.ac.th

Submitted final draft: 15 September $2020 \quad$ Accepted: 23 September $2020 \quad$ http://doi.org/10.46754/jssm.2021.02.006

\begin{abstract}
The objective of this study is to apply a response surface methodology in optimizing pulsed vacuum osmotic dehydration to achieve sufficient solids in a gel matrix using a diluted solution. Application of PVOD enrichment of antioxidant compounds and nutrients is also investigated. The process variables are agar-gel bulk density $(0.65-0.85 \mathrm{~g} /$ $\mathrm{ml})$, sucrose concentration $(30-60 \% \mathrm{w} / \mathrm{w})$ and vacuum impregnation time (10-30 $\mathrm{min})$. The results show that process variables, especially sucrose concentration, significantly affected moisture content (MC), water loss (WL) and solids gain (SG) of a model food. A quadratic model was fitted for $\mathrm{WL}, \mathrm{SG}$, weight reduction and total soluble solids prediction $\left(R^{2}\right.$ 0.997 - 0.999). The prediction of total soluble solids was the most precise $\left(X^{2} 0.095\right)$. Optimum conditions were $32.58 \% \mathrm{w} / \mathrm{w}$ for sucrose content, $0.8 \mathrm{~g} / \mathrm{ml}$ in bulk density and 14.34 min vacuum time. The physiological compounds can be sufficiently introduced into the model food with a diluted solution. The results may be applied to the development of new innovative products that provide the desired compound level and functionality. This will increase product value, utilization of agricultural produce, and reduce the loss of freshness in seasonal produce, especially tropical fruits.
\end{abstract}

Keywords: Sustainability, functional food, mass transfer, osmotic dehydration, physiological compounds, response surface methodology.

\section{Introduction}

Pulsed vacuum osmotic dehydration (PVOD) is an osmotic dehydration (OD) process assisted by the application of vacuum pressure. It refers to the maintenance of food in osmotic solution for a long term after a short period under vacuum (Zhao \& Xie, 2004). The PVOD operation consists of three steps. In step one, the food sample is soaked in an osmotic medium like sucrose syrup or syrup mixed with active substances, and then immediately subjected to vacuum pressure ( $\sim 50-100 \mathrm{mbar})$ for a short time (10-30 $\mathrm{min})$ in a closed tank (Fito et al., 2001: Chottanom et a.l, 2016). The air and native liquids are removed from food tissue and the expansion of pores occurs due to a pressure gradient. In step two, atmospheric pressure is restored in the tank. The impregnation of pores by external solution and relaxation of deformation phenomena of food tissues will simultaneously occur. In step three, the food sample is soaked in osmotic solution for a certain period ( $180-360 \mathrm{~min})$. Vacuum could speed up processing time and allow a reduction in energy during the process (Corzo et al., 2007). Mass transfer increases because loss of air may increase contact area between the external solution and food tissue as a consequence of pore impregnation. PVOD is useful for infusing solutions into the porous structure of food samples due to the action of hydrodynamic mechanisms promoted by pressure gradient (Fito et al., 2001). Therefore, PVOD may introduce desirable solutes into porous food structures and modify their original composition to develop new products (Schulze et al., 2014); Betoret et al., 2012; Chottanom et al., 2016; Jesus Junqueira et al., 2017; An et al., 2019).

There are numerous reports of PVOD increasing mass transfer with many process 
variables. However, the concentration of osmo-active solute in the osmotic solution, food structure and molecular weight of added compounds will affect the rate of food infusion. Therefore, there is a need for rigorous optimization in using PVOD, focusing on vacuum input, solution concentration and food characteristics. Moreover, the effects of certain structure-parameters, such as a bulk density on mass transfer, have not been clearly analyzed.

Response surface methodology (RSM) is a useful statistical technique which has been applied in research to optimize processes with complex variables. It has been used to determine the effects of variables in mass transfer during OD and PVOD. However, the optimum levels of vacuum pressure, concentration of osmotic solution and dehydration time may vary because of the differences in food microstructure (Fermin \& Corzo, 2005; Alam et al., 2010; Panarese et al., 2013). The formulation of minimallyprocessed foods with high $\mathrm{a}_{\mathrm{w}}$, the application of PVOD seemed to be advantageous over OD, particularly in the case of fruits with high porosity levels, such as apples (Mujica-Paz et al., 2003). The vacuum is very useful for the process conducted with a viscous solution (Chottanom et al., 2016). The optimum process variables providing appropriate values of water removal and solute gain obtained from the optimization step will be useful for food formula modification in new product developments.

The objective of this study is to investigate the effects of process variables. such as bulk density, sucrose concentration and vacuum impregnation time, on mass transfer of food samples prepared from agar. The agar was used as a food model because it may be prepared for a specific bulk density/porosity for developing new products with low calories and high physiological compounds. RSM was used to optimize PVOD so as to achieve sufficient solids in the gel matrix with low sucrose gain. In addition, an optimum condition was applied for food formula modification in the model food product, focusing on the enrichment of antioxidants and nutritive compounds.
The optimum processes from this project may be applied to food processing in a larger scale that uses agricultural raw materials. This will increase product value, utilization of agricultural produce, and reduce the loss of freshness in seasonal fruits and vegetables.

\section{Materials and Methods}

\section{Preparation of Model Food Cubes}

The model food cubes (MFC) were prepared from agar gel according to Rózek et al. (2010) with modifications. A total of $3.3 \mathrm{~g}$ to $6.5 \mathrm{~g}$ of agar powder (Titan Biotech LTD., Rajasthan, India) and $10 \mathrm{~g}$ of sucrose were dissolved in $100 \mathrm{~g}$ distilled water at $95^{\circ} \mathrm{C}$ to obtain $0.65-0.85$ $\mathrm{g} / \mathrm{ml}$ of bulk density. The mixture was heated again in a microwave oven (600 watts) for 10 min to obtain perfectly dissolved gel. The gel solution was poured into a plastic mould and cooled at room temperature $(2 \mathrm{~h})$. The agar gel was then allowed to set for $6 \mathrm{~h}$ at $8+2$. The gel was then cut into cubes $(1 \times 1 \times 1 \mathrm{~cm})$ for further study. The variation in bulk density value of each MFC was accepted at $<5 \%$.

\section{Pulsed Vacuum Osmotic Dehydration (PVOD)}

The MFC were first weighed $(100 \mathrm{~g})$ and subjected to PVOD under different conditions, such as variation in bulk density of the agar gel $(0.65-0.85 \mathrm{~g} / \mathrm{ml})$, sucrose concentration $(30-60 \% \mathrm{w} / \mathrm{w})$ and vacuum impregnation time (10-30 min). All treatments were performed at MFC to sucrose solution ratio of 1:2(w/w) before they were put into the vacuum chamber. The vacuum pressure value was selected at 150 milibar and applied for 10 to $30 \mathrm{~min}$ using a Gast-model DOA-P504-BN vacuum pump (Gast Manufacturing, MI, USA) Thereafter, the samples were restored to atmospheric pressure for $180 \mathrm{~min}$ (Moraga et al., 2009). The impregnated agar gels were drained for $10 \mathrm{~min}$ and the mass transfer parameters determined as described below.

In addition, enrichment of physiologically active compounds (analytical grade) in the 
model food was carried out. A total of $6 \%(\mathrm{w} / \mathrm{w})$ Ascorbic acid (AA), 3\% (w/w) Gallic acid (GA) and $1.2 \%(\mathrm{w} / \mathrm{w})$ calcium lactate $(\mathrm{CAL})$ were added into the OD medium, in which the optimum process variables were determined from an optimization step. The concentrations of added substances were in ranges that had been reported in numerous studies (Rózek et al., 2010; Hironaka et al., 2011; Dermesonlouoglou et al., 2016).

\section{Experimental Design}

RSM was applied to the experimental data using the Design-Expert ${ }^{\circledR}$ version 7.1 statistical software (Stat-Ease Inc, MN, USA). The central composite rotatable design (CCRD) with three factors was employed to generate experimental design points (Run). Natural (uncoded form) values corresponding to coded values of each variable are shown in Table 1. CCRD included a $2^{3}$ design with nine factorial points, six axial points and four replicate center points, giving a total of 18 combinations (see Table 2).

Table 1: Coded and natural values of process variables used in the experimental design

\begin{tabular}{lcccccc}
\hline \multirow{2}{*}{ Process Variables } & \multirow{2}{*}{ Symbols } & \multicolumn{5}{c}{ Coded and Natural Values } \\
\cline { 3 - 7 } & & $\mathbf{- 1 . 6 8 2}$ & $\mathbf{- 1}$ & $\mathbf{0}$ & $\mathbf{+ 1}$ & $\mathbf{+ 1 . 6 8 2}$ \\
\hline Bulk density $(\mathrm{g} / \mathrm{ml})$ & $\mathrm{X}_{1}$ & 0.58 & 0.65 & 0.75 & 0.85 & 0.92 \\
Concentration $(\% \mathrm{w} / \mathrm{w})$ & $\mathrm{X}_{2}$ & 19.77 & 30 & 45 & 60 & 70.25 \\
Vacuum pressure time $(\mathrm{min})$ & $\mathrm{X}_{3}$ & 3.18 & 10 & 20 & 30 & 36.82 \\
\hline
\end{tabular}

\section{Statistical Analysis and Optimization}

The first-order equation (Eq.1) and secondorder polynomial equation (Eq.2) were applied in fitting to the experimental data of each dependent variable as follows:

$$
\begin{aligned}
& Y_{k}=a_{0}+a_{1} X_{1}+a_{2} X_{2}+a_{3} X_{3}+a_{12} X_{1} X_{2}+a_{13} X_{1} X_{3}+a_{23} X_{2} X_{3}+\varepsilon \\
& Y_{k}=a_{0}+a_{1} X_{1}+a_{2} X_{2}+a_{3} X_{3}+a_{11} X_{1}^{2}+a_{22} X_{2}^{2}+a_{33} X_{3}^{2}+a_{12} X_{1} X_{2}+a_{13} X_{1} X_{3}+a_{23} X_{2} X_{3}+\varepsilon
\end{aligned}
$$

where $Y_{k}$ represent response variable, xi represent the independent variables $\left(X_{1}=\right.$ bulk density, $=X_{2}$ sucrose concentration, $X_{3}=$ vacuumimpregnation time). Where $a_{0}$ is the value of fitted response at the center point of design, i.e. point $(0,0,0), a_{1}, a_{2}, a_{3}, a_{11}, a_{22}, a_{33}, a_{12}, a_{13}, a_{23}$ are coefficients, and $\varepsilon$ is a random error term.

Regression analysis and analysis of variance (ANOVA) were performed for fitting the models represented by Eq. 1 and Eq. 2, and to examine the statistical significance of the model terms, employing a manual technique. Goodness-to-fit of the models was determined using $P$-value, lack-of-fit test, coefficient of determination $\left(R^{2}\right)$, standard deviation $(S D)$, coefficient of variation $(\mathrm{CV})$ and Chi-square $\left(x^{2}\right)$ test.

The 3-D surface was drawn by keeping one variable constant at the center point and varying the other two variables within the experimental range. Optimal conditions for PVOD of MFC depended on bulk density, sucrose concentration and impregnation time, which were obtained using the predictive equations of RSM. The optimization of PVOD was aimed at finding the appropriate level of the three factors to provide the highest possible SG and TSS by using a diluted sucrose solution. 


\section{Determination of Mass Transfer Parameters}

After PVOD, moisture content $(M C)$ in the MFC expressed in percentage values were analyzed according to a standard method (AOAC, 2000). Total soluble solids (TSS) expressed in $\%$ $\mathrm{w} / \mathrm{w}$ were measured (ATAGO refractometer). Water loss (WL), solids gain (SG) and weight reduction (WR) values expressed in percentage were determined according to Equations 3 to 5 as follows:

$$
\begin{aligned}
& W L(\%)=\frac{M C_{i} m_{i}-M C m_{f}}{m_{i}} \times 100 \\
& S G(\%)=\frac{S_{f} m_{f}-S_{i} m_{i}}{m_{i}} \times 100 \\
& W R(\%)=\frac{m_{i}-m_{f}}{m_{i}} \times 100
\end{aligned}
$$

where is the MFC weight, $M C$ is the moisture content $(\mathrm{g} / \mathrm{g}$ sample), is the solid content $(\mathrm{g} / \mathrm{g}$ sample); and, the sub-indices and are the initial and final values, respectively.

\section{Determination of Bulk Density}

Measurement of bulk density of the samples was determined by water displacement. The samples were weighed $(\sim 1.5-2.5 \mathrm{~g})$ with a digital balance and put into a glass pycnometer (filling volume $100 \mathrm{~mL}$ ). The pycnometer was filled with distilled water to measure the volume of the samples (Nieto et al., 2004).

\section{Determination of Ascorbic Acid Content}

AA content was determined using highperformance liquid chromatography (HPLC) following the protocols of Lui et al. (2013) with modifications. Briefly, MFC was dissolved in $2.5 \% \mathrm{w} / \mathrm{v}$ metaphosphoric acid. Clear extracts $(20 \mu \mathrm{L})$ were injected into an Inertsil® ODS-3 column $(4.6 \times 250 \mathrm{~mm})$ of a Shimadzu HPLC system (Shimadzu Co., Kyoto, Japan). The mobile phase was pure deionized water adjusted with metaphosphoric acid to $\mathrm{pH} 2.2$. Flow rate and column temperature were $0.8 \mathrm{~mL} / \mathrm{min}$ and 40 , A UV-vis photodiode array detector at 254 nm was applied to quantify the AA. Results were calculated using L-ascorbic acid as an external standard and expressed as $\mathrm{mg} / 100 \mathrm{~g}$ sample.

\section{Determination of Gallic Acid Content}

MFC samples were dissolved in $80 \% \mathrm{v} / \mathrm{v}$ methanol following the modified method of Liu et al. (2013). GA analysis was conducted using the HPLC system as described by Loypimai, et al. (2016). The mobile phase for GA evaluation was deionized water-acetonitrile with a flow rate of $0.6 \mathrm{~mL} / \mathrm{min}$. The gallic acid was quantified using a UV-diode array detector at $278 \mathrm{~nm}$. The gallic acid content was expressed as $\mu \mathrm{g} / \mathrm{g}$ sample.

\section{Determination of Sucrose Content}

Sucrose content was extracted following the procedure of Jacob \& Paliyath (2012) with modifications. Briefly, MFC were dissolved in methanol. Clear extracts $(20 \mu \mathrm{L})$ were injected into an Inertsil@ NH2 column $(4.6$ x $250 \mathrm{~mm})$ of the HPLC system. A refractive index detector was used to quantify sucrose. The mobile phase consisted of acetonitrile/distilled water $(85: 15)$ with a flow rate of $1.5 \mathrm{~mL} / \mathrm{min}$, and column temperature was kept at 40 . Sucrose content was calculated using sucrose (HPLC grade) as an external standard and expressed as $\mathrm{mg} / \mathrm{g}$ sample.

\section{Determination of Calcium Content}

Calcium content was determined as described by AOAC (2000), with slight modifications. Briefly, MFC were mixed with a 2:1 nitric acid/perchloric acid ratio. The mixture was allowed to stand for $1 \mathrm{~h}$ before the digestive process in the digestion block (AIM600, A.I. Scientific, Australia). Concentrations of calcium were determined using an Optima 8000 DV inductively coupled plasma-optical emission spectrometer (ICP-OES), (Perkin-Elmer, Waltham, MA, USA). Measurements were taken at the $257.61 \mathrm{~nm}$ spectral line. Calcium content was expressed as $\mathrm{mg} / 100 \mathrm{~g}$ sample. 


\section{Results and Discussion}

The treatment combinations were obtained from a central composite design and all results are shown in Table 2. The model food had about $82.77 \%$ MC. The MC decreased after PVOD to a range of between $49.82 \%$ and $76.74 \%$. The moisture removal was relatively low compared to the case of other food (Chottanom, 2012 , 2016). WL was in the range of $8.77 \%$ to $32.28 \%$. Whereas, solute values were quite high at around $12.25 \%$ to $31.11 \%$ of SG, and about $13 \%$ to $24.5 \%$ of TSS were observed. Therefore, weight gain (-WR value) was found in many process conditions, particularly at a concentration lower than $60 \% \mathrm{w} / \mathrm{w}$. Regression analysis was applied to correlate the mean values of MC, WL, SG, WR and TSS with the three independent variables $\left(\mathrm{X}_{1}, \mathrm{X}_{2}, \mathrm{X}_{3}\right.$, ). The estimated regression coefficients of the linear, interaction and quadratic terms for the response variables, along with the corresponding $\mathrm{R}^{2}, \mathrm{CV}$ and $\mathrm{SD}$, are presented in Table 3.

Analysis of variance showed that the regression model could significantly explain for the total variability in all responses. The changes in WL, SG, WR and TSS during PVOD were appropriately described by a quadratic model. In all cases, the values were greater than 0.99 , indicating a good fit. Whereas, a linear model appropriated for $\mathrm{MC}$ was $R^{2}=0.997$. In this study, the SD values were relatively low when compared with the mean value of each response.

Table 2: Treatment combinations obtained from CCRD and response values

\begin{tabular}{lllllcccc}
\hline Run & \multicolumn{7}{c}{ Process variables } & \multicolumn{5}{c}{ Responses } \\
\hline & $\mathrm{X} 1$ & $\mathrm{X} 2$ & $\mathrm{X} 3$ & $\mathrm{MC}$ & $\mathrm{WL}$ & $\mathrm{SG}$ & $\mathrm{TSS}$ & WR \\
1 & 0.65 & 30 & 10 & 74.21 & 10.17 & 12.25 & 15.00 & -2.07 \\
2 & 0.85 & 30 & 10 & 72.48 & 8.77 & 12.37 & 15.00 & -3.60 \\
3 & 0.65 & 60 & 10 & 57.27 & 29.64 & 31.11 & 22.00 & -1.48 \\
4 & 0.85 & 60 & 10 & 55.67 & 23.33 & 26.52 & 21.10 & -3.18 \\
5 & 0.65 & 30 & 30 & 73.48 & 9.90 & 14.09 & 17.50 & -4.19 \\
6 & 0.85 & 30 & 30 & 62.97 & 13.65 & 18.77 & 17.80 & -4.12 \\
7 & 0.65 & 60 & 30 & 55.80 & 27.78 & 24.57 & 24.50 & 2.21 \\
8 & 0.85 & 60 & 30 & 55.64 & 25.68 & 23.25 & 23.60 & 2.43 \\
9 & 0.58 & 45 & 20 & 65.70 & 19.98 & 22.56 & 20.00 & -2.58 \\
10 & 0.92 & 45 & 20 & 62.14 & 16.10 & 21.11 & 19.00 & -4.01 \\
11 & 0.75 & 19.77 & 20 & 76.74 & 4.77 & 16.64 & 13.00 & -1.27 \\
12 & 0.75 & 70.23 & 20 & 49.82 & 32.28 & 27.13 & 25.00 & 5.14 \\
13 & 0.75 & 45 & 3.18 & 67.57 & 16.10 & 21.65 & 16.60 & -5.55 \\
14 & 0.75 & 45 & 36.82 & 59.73 & 17.43 & 20.45 & 21.80 & -3.02 \\
15 & 0.75 & 45 & 20 & 64.32 & 16.81 & 20.53 & 17.20 & -3.72 \\
16 & 0.75 & 45 & 20 & 64.32 & 16.81 & 20.53 & 17.20 & -3.72 \\
17 & 0.75 & 45 & 20 & 62.85 & 16.29 & 20.11 & 17.60 & -3.82 \\
18 & 0.75 & 45 & 20 & 64.32 & 16.30 & 20.10 & 17.60 & -3.81 \\
\hline & & & & & & & & \\
\hline
\end{tabular}


Table 3: ANOVA and regression coefficients of models for response values (in coded units)

\begin{tabular}{|c|c|c|c|c|c|c|c|c|c|c|c|}
\hline \multirow[t]{2}{*}{ Variables } & \multirow[t]{2}{*}{ DF } & \multicolumn{5}{|c|}{ Estimated coefficients } & \multicolumn{5}{|c|}{$P$-value* } \\
\hline & & MC & WR & WL & SG & TSS & MC & WR & WL & SG & TSS \\
\hline Model & 9 & 63.61 & -3.77 & 16.51 & 20.29 & 17.4 & $<0.0001$ & $<0.0001$ & $<0.0001$ & $<0.0001$ & $<0.0001$ \\
\hline $\mathbf{X}_{1}$ & 1 & -1.47 & -0.39 & -0.92 & -0.26 & -0.26 & 0.0025 & $<0.0001$ & 0.0006 & 0.0551 & 0.0075 \\
\hline $\mathbf{X}_{2}$ & 1 & -7.62 & 1.81 & 8.07 & 6.04 & 3.18 & $<0.0001$ & $<0.0001$ & $<0.0001$ & $<0.0001$ & $<0.0001$ \\
\hline $\mathbf{X}_{3}$ & 1 & -1.83 & 0.8 & 0.54 & -0.26 & 1.43 & 0.0005 & $<0.0001$ & 0.0125 & 0.0539 & $<0.0001$ \\
\hline $\mathbf{X}_{1} \mathbf{X}_{2}$ & 1 & 1.31 & 0.44 & -1.34 & -1.34 & -0.32 & 0.022 & 0.9688 & 0.0003 & $<0.0001$ & 0.0116 \\
\hline $\mathbf{X}_{1} \mathbf{X}_{3}$ & 1 & -0.92 & 1.49 & 1.17 & 0.98 & -0.016 & 0.0888 & $<0.0001$ & 0.0007 & 0.0002 & 0.8714 \\
\hline $\mathbf{X}_{2} \mathbf{X}_{3}$ & 1 & 1.09 & 0.17 & -0.52 & -2.26 & 0.016 & 0.0483 & $<0.0001$ & 0.0462 & $<0.0001$ & 0.8714 \\
\hline$X_{1}^{2}$ & 1 & & 2.02 & 0.69 & 0.64 & 0.73 & - & 0.0018 & 0.004 & 0.0007 & $<0.0001$ \\
\hline $\mathbf{X}_{2}^{2}$ & 1 & & -0.18 & 0.86 & -1.11 & 0.87 & - & $<0.0001$ & 0.0011 & $<0.0001$ & $<0.0001$ \\
\hline $\mathbf{X}_{3}^{2}$ & 1 & & & 0.24 & 0.36 & 0.63 & - & 0.0014 & 0.2006 & 0.0173 & $<0.0001$ \\
\hline Residual & 8 & & & & & & & & & & \\
\hline Lack of Fit & 5 & & & & & & 0.1202 & 0.0530 & 0.0801 & 0.1261 & 0.3575 \\
\hline Pure Error & 3 & & & & & & & & & & \\
\hline \multirow[t]{4}{*}{ Cor. Total } & 17 & & & & & & & & & & \\
\hline & & 0.977 & 0.999 & 0.996 & 0.998 & 0.997 & & & & & \\
\hline & & 2.19 & 5.61 & 3.64 & 2.12 & 1.44 & & & & & \\
\hline & & 1.39 & 0.13 & 0.65 & 0.43 & 0.27 & & & & & \\
\hline
\end{tabular}

*The values, $\mathrm{P}<0.05, \mathrm{P}<0.001$, and $\mathrm{P}<0.0001$ mean significant effect of the model or terms at $95 \%, 99 \%$, and $99.9 \%$, respectively.

The CV values of most responses were less than $5 \%$. Moreover, the lack of fit value of each response was insignificant, indicating adequate reliability of the linear $(\mathrm{MC})$ or quadratic $(\mathrm{WL}$, SG, WR and TSS) models in describing mass transfer phenomenon in MFC-PVOD.

MC was an initial parameter used for analysis of mass transfer. The linear model showed a better fit for MC when compared to the quadratic model (data not shown). In comparison with the P-value, the concentration had the highest effect on moisture removal, followed by time and bulk density, because a high concentration gradient between MFC and OD medium was presented.

Generally, vacuum impregnation could decrease up to $60 \% \mathrm{MC}$ in food, depending on process conditions. The factors influencing moisture removal included food properties and environmental conditions, especially temperature, pressure, agitation and the medium used (Fito et al., 2001; Mujica-Paz et al., 2003; Giraldo et al.; 2003; Shi, J. \& Xue Jun, S., 2009; Chottanom et al., 2012). In this study, approximately, the highest MC decrease was recorded at $40 \%$ within the experimental conditions. Water removal from agar gel was quite difficult because of the absorption ability of the agar's homogenous polysaccharide molecules. Generally, reduction of $\mathrm{MC}$ in food was up to $30-40 \%$ with the conventional process (Mujica-Paz et al., 2003; Giraldo, et al.; 2003; Chottanom et al., 2012), and could be significantly increased by using vacuum impregnation (Chottanom et al., 2016, Jesus Junqueira et al., 2017).

Besides the $P$-value, the coefficient value could be used to describe the effect of process variables. The coefficient values from the coded 


$$
\begin{aligned}
M C= & 123.38979-35.62385 X_{1}-1.30899 X_{2}+0.17821 X_{3}+0.874 X_{1} X_{2}-0.918 X_{1} X_{3}+ \\
& 7.28^{E-03} X_{2} X_{3}
\end{aligned}
$$

model (Table 3) were more useful than those from the uncoded model described in Equation 6 in analysing the effects of the process variable. However, presentation of the response surface using the actual conditions might provide a better understanding.

Figures $1 \mathrm{a}$ and $1 \mathrm{~b}$ show the variations of $\mathrm{MC}$ in MFC as a function of $\mathrm{X}_{1}$ and $\mathrm{X}_{2}$, and $\mathrm{X}_{2}$ and $\mathrm{X}_{3}$, respectively. The regular reduction of moisture was clearly observed, The predicted value of moisture content was in the range of 58$74 \%$ throughout PVOD. In this study, the effect of $\mathrm{X}_{1}$ or $\mathrm{X}_{3}$ variables gradually decreased when the $\mathrm{X}_{2}$ level increased.

WL was significantly affected by the three process variables and all model terms, with the exception of the $X_{3}^{2}$ term (Table 3). The concentration seemed to provide the strongest effect. The estimate coefficients both on linear and quadratic terms indicated the maximum positive effect of concentration on WL. Effect of time $(P$-value $=0.0125)$ was less when compared to concentration $(P<0.0001)$ and bulk density $(P=0.0006)$. The response surface showed that WL increased regularly as the

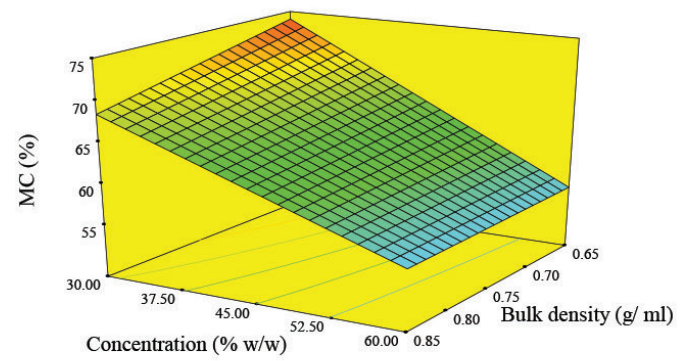

(a) concentration increased (Figures $2 \mathrm{a}$ and $2 \mathrm{~b}$ ). An effect of bulk density on WL was significantly lower than that of concentrations, and the highest WL was recorded at the lowest bulk density level $(0.65 \mathrm{~g} / \mathrm{ml})$. However, the effect of bulk density gradually decreased at a lower concentration level (Figure 2a). In this study, the effect of vacuum time was less pronounced (Figure 2b), in accordance with the regression variables in Table 3. In our study, we assumed the gel samples had similar porosity at a range of between 0.02 and 0.035 . Therefore, diffusion of water molecules was due to the driving force in OD (atmospheric pressure recovery procedure), which was the effect of the difference in chemical potential of the components (mostly water), instead of the effect of vacuum pressure gradient. In accordance with OD (without vacuum), Rózek et al. (2010) found that WL of agar gel during OD processing increased with longer soaking time, and they noted that the increase in immersion time and soluble solid concentration in the osmotic agent promoted the loss of water from agar gel, possibly due to the increase of osmotic gradient in the food particles and osmotic medium.

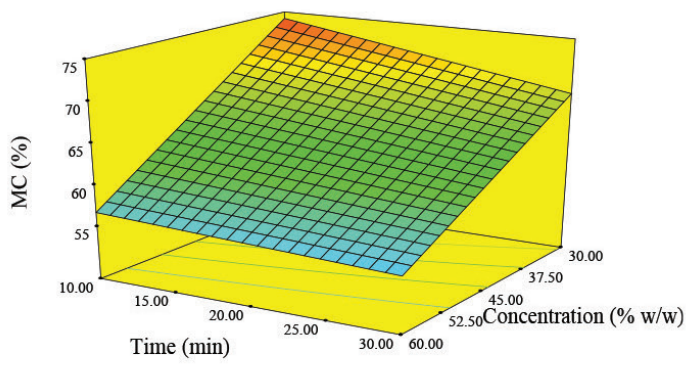

(b)

Figure 1: Response surface plots of moisture content (MC) in model food cubes

$$
\begin{aligned}
& W L=30.17818-96.45382 X_{1}+0.93263 X_{2}-0.76681 X_{3}-0.89507 X_{1} X_{2}+ \\
& 1.17095 X_{1} X_{3}-3.44^{E-03} X_{2} X_{3}+69.40341 X_{1}^{2}+3.84^{E-03} X_{2}^{2}+2.43^{E-03} X_{3}^{2}
\end{aligned}
$$




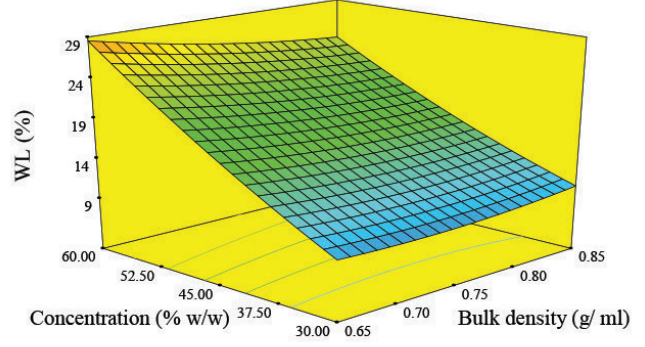

(a)

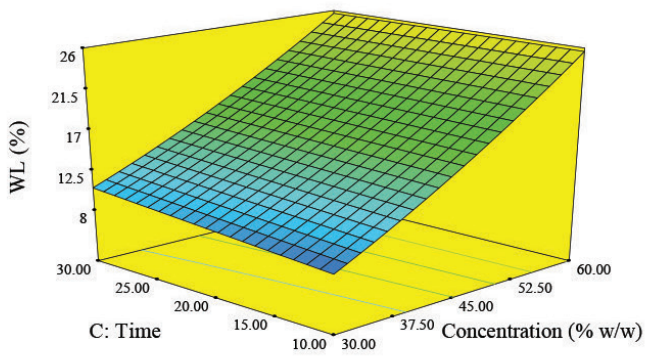

(b)

Figure 2: Response surface plot of water loss (WL) in model food cubes

Solids gain (SG) value was a vital parameter in OD that could alter the food characteristics (physical, chemical and organoleptic properties), besides changing its product caloric value (Jalaee et al., 2011; Phisut, 2012) and prolonging shelf-life. The effect of process variables on $\mathrm{SG}$ values is presented in Table 3. The concentration had a strong effect on $\mathrm{SG}$ as well as WL. All interaction terms $\left(\mathrm{X}_{1} \mathrm{X}_{2}\right.$, $\mathrm{X}_{2} \mathrm{X}_{3}, \mathrm{X}_{1} \mathrm{X}_{3}$ ) were significant (Table 3), and their effects were shown in Figures $3 \mathrm{a}$ and $3 \mathrm{~b}$.

The effect of the interaction terms was clearly shown at high concentration level. The increase in SG induced by increasing concentration was observed when a bulk density of MFC was low, but SG rate seemed to reduce at a high level of bulk density (Figure 3a). However, the effect of $X_{1}$ variable wasn't important when the concentration level decreased. In this study with gel structure, the negative effect of high concentration was not observed. SG continuously increased with an increase of concentration, while time seemed to bring a negative effect.

Compared with plant-based foods, as the concentration increased, the OD solution would become more viscous and had more difficulty in penetrating the tissue. The solution at a higher concentration encouraged the formation of a layer of solutes at the plant material, which resulted in a lower solids uptake into the complex structure of the food. Mújica-Paz et al. (2003), Ito et al. (2007) and Corrêa et al. (2010) demonstrated that a concentrated medium could penetrate less well into the fruit structure compared with diluted medium, causing high viscosity that rendered the penetration of solutes more difficult. Giraldo et al. (2003) reported that a high rate of SG at the initial time might promote the creation of a dense layer of solutes like sucrose at the surface of the impregnated product and negatively affecting mass transfer in OD process. The rate of SG in apples had been observed to increase by concentration, and then significantly decrease with OD concentration when the concentration was up to $50 \% \mathrm{w} / \mathrm{w}$ (Mújica -Paz et al., 2003).

Effective porosity and fibrous structure tissue of plants had been reported to react with vacuum pressure. Spinach tissues showed gas release at a much lower pressure than apple (rigid microstructure), and its impregnation required a much higher pressure. These differences in pressure threshold could be caused by the narrow pores in spinach and possibly by changes in leaf volume (Panarese et al., 2003).

In the case of agar gels (a mixture of linear agarose polysaccharides and a heterogeneous mixture of smaller molecules called agaropectin), the solid transfer behavior was not similar to plant-based foods. Increasing concentration did not delay the SG rate. Generally, differences in biological structural characteristics of food materials might affect mass transfer of osmotically dehydrated food.

For plant materials, mass transfer was associated with a semipermeable membrane and cell arrangement. In this study, a continuous 
increase of SG in MFC could be explained by these reasons. The gel structure had no semipermeable membrane. The permeability mainly depended on the concentration gradient, porosity, space, contact area and bulk density. Besides, agarose content was affected by pore size and hydrogen-bonding with water molecules.

The use of vacuum pressure at the beginning of the osmotic process would result in the release of gases trapped in the in agar gel pores, which was then be replaced with a concentrated solution causing the continuity of the solute uptake. However, SG was slightly low at high concentration and long vacuum impregnation. This might be caused by the reduction of pore size that depended on the mechanical resistance of the solid matrix and pressure levels (Fito et al. 2001). For example, vacuum pressure and time resulted in an increase in SG in guavas samples with a rigid structure (Corrêa et al., 2010). However, for agar gel samples, the gel structure was easily damaged by the vacuum pressure and might result in a slight loss of solids during OD. However, interaction between pressureresistance ability of the samples, vacuum time and vacuum level should be taken into account.

$$
\begin{aligned}
& S G=3.00118-77.76999 X_{1}+1.8187 X_{2}-0.22821 X_{3}-0.89381 X_{1} X_{2}+0.97977 X_{1} X_{3}- \\
& 0.015052 X_{2} X_{3}+63.85999 X_{1}^{2}-4.94^{E-03} X_{2}^{2}+3.61^{E-03} X_{3}^{2}
\end{aligned}
$$

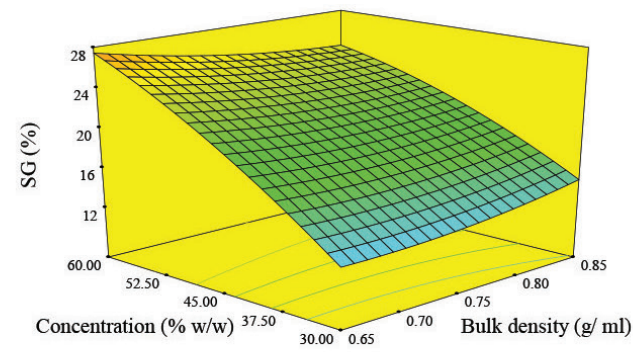

(a)

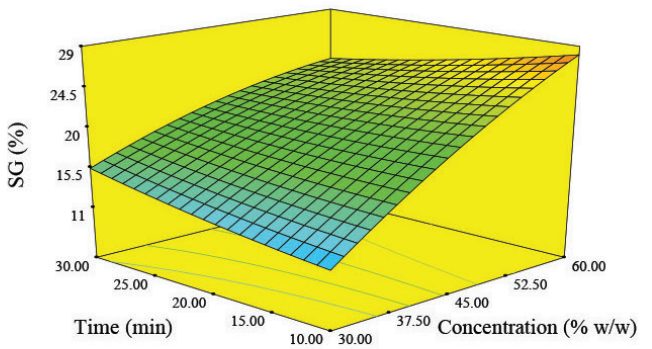

(b)

Figure 3: Response surface plot of solids gain (SG) in model food cubes

Total soluble solids (TSS) was dependent upon the main effects (linear and quadratic terms), while the effect of the interaction terms was low (Table 3). The mass transfer characteristic of TSS slightly differed from SG, where the latter was significantly affected by interaction terms (as described above). The increasing pattern of TSS is shown at Figures $4 \mathrm{a}$ and $4 \mathrm{~b}$. The TSS continuously increased with concentration and time, and its increase
TSS was mainly caused by sucrose molecules in a solution. This different pattern between SG and TSS at high concentration level could be explained by the mass transfer of sucrose molecules simultaneously with a slight loss of solids in the gel during OD or PVOD. This could result in a somewhat reduction of SG value (Figure $3 b$ ), while sucrose diffusion into a gel matrix was still continuous (Figure $4 b$ ).

$$
\begin{aligned}
& \text { TSS }=51.28653-102.69154 X_{1}+0.018702 X_{2}-0.10061 X_{3}-0.21083 X_{1} X_{2}- \\
& 0.01625 X_{1} X_{3}+1.08^{E-04} X_{2} X_{3}+73.23957 X_{1}^{2}+3.88^{E-03} X_{2}^{2}+6.26^{E-03} X_{3}^{2}
\end{aligned}
$$




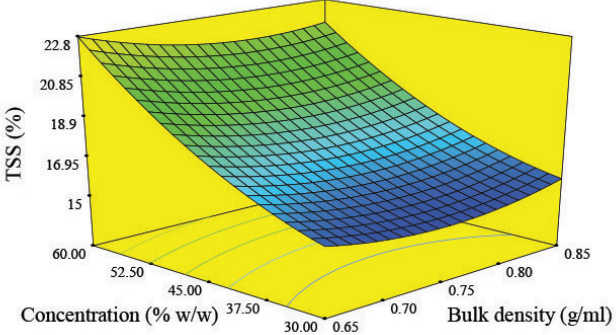

(a)

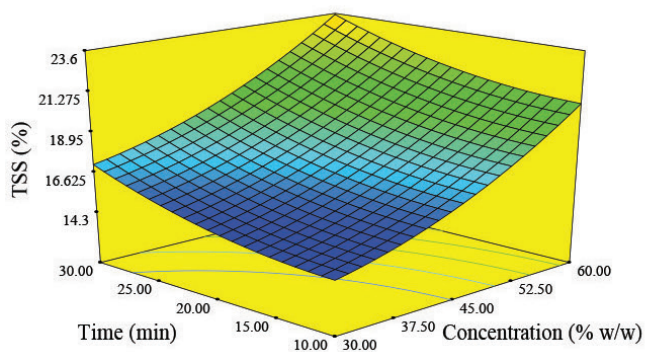

(b)

Figure 4: Response surface plot of total soluble solids (TSS) in food model cubes

Weight reduction (WR) effected by the three factors is shown at Table 3 and Figure 5. All the model terms were significant in WR, with the exception of the $\mathrm{X}_{1} \mathrm{X}_{2}$ term (Table 3). The concentration was the most affected by WL (Table 3, Equation 10). The impregnated MFC had negative weight reduction values, indicating that the samples had absorbed the sucrose solution during PVOD, but with low WL. However, increasing WR could be observed at the highest concentration level that provided a high amount of WL. The amount of water removal from a gel sample was low, but with high SG because of the absorption ability of homogenous polysaccharide molecules that provided a greater influence than the driving force from the concentration difference at low concentration level $(<60 \% \mathrm{w} / \mathrm{w})$.

$$
\begin{aligned}
& W R=34.73731+38.319 X_{1}-88543 X_{2}-0.62661 X_{3}-1.26654^{E-0.003} X_{1} X_{2}+0.4412 X_{1} X_{3}+ \\
& 9.90073^{E-003} X_{2} X_{3}+17.0974 X_{1}^{2}+8.9809^{E-03} X_{2}^{2}-1.7961^{E-003} X_{3}^{2}
\end{aligned}
$$

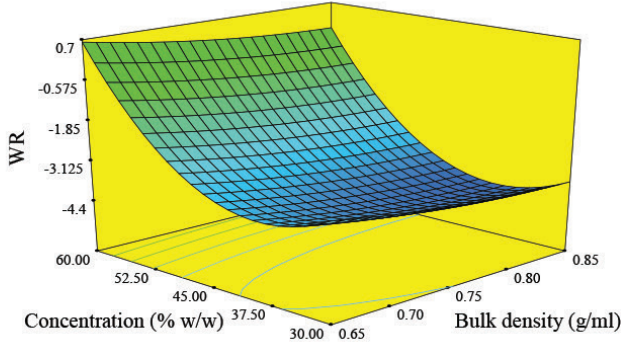

(a)

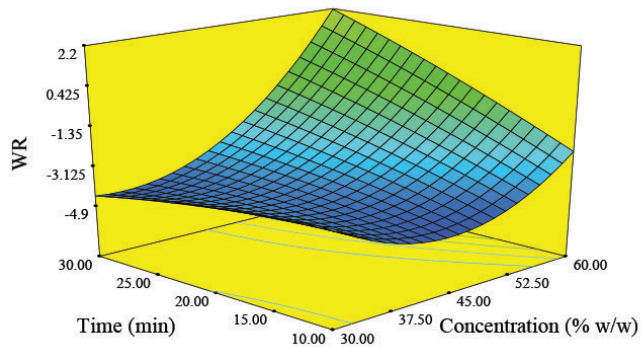

(b)

Figure 5: Response surface plot of weight reduction (WR) in food model cubes

In order to optimize the conditions in PVOD through numerical analysis, which would find a point that maximized the desirability function - an equation importance of " 3 " was given to the process parameters (bulk density, concentration and time). The analysis showed that the optimum process conditions for bulk density, concentration and time were $0.80 \mathrm{~g} / \mathrm{ml}$,
$32.85{ }^{\circ}$ Brix and $14.34 \mathrm{~min}$, respectively, and the corresponding values of MC, WL, SG and TSS were shown in Table 4.

The overall desirability, which ranged from zero outside of the limits to one at the goal, was 1. The optimum conditions were experimentally verified. The experimental value of $\mathrm{MC}$ was relatively higher than the predicted one, while the 
Table 4: The solution along with predicted and experimental response-values.

\begin{tabular}{lllc}
\hline \multicolumn{1}{c}{ Variables } & \multicolumn{1}{c}{ Predicted value } & Experimental value & $\boldsymbol{x}^{\mathbf{2}}$ \\
\hline $\mathrm{MC}^{* *}$ & 71.04 & $75.34 \pm 2.13$ & 0.817 \\
$\mathrm{WL}$ & 10.03 & $8.05 \pm 1.21$ & 1.759 \\
$\mathrm{SG}$ & 14.09 & $11.25 \pm 1.41$ & 1.999 \\
$\mathrm{TSS}$ & 14.98 & $14.50 \pm 0.50$ & 0.095 \\
\hline
\end{tabular}

*Values are means $\pm S D$ of the triplicate experiment. $(0.05$, D.F. $=3)=5.991$

**Total solids were approximately $24.68+2.16 \%$

predicted values of WL, SG and TSS were less than the experimental ones. However, statistical analysis showed an insignificant difference between the experimental values and predicted values when described by values. All values in Table 4 were lower than the critical value (5.99). The prediction of TSS was, therefore, more accurate than MC, WL and SG.

The effect of adding physiological compounds into the agar gel in PVOD is shown in Table 5. The optimizing conditions obtained above could provide AA, GA and calcium contents equivalent to the food that was the source of these substances. Under this condition, the consumption of $100 \mathrm{~g}$ of MFC would provide an intake of approximately $953.18 \mathrm{mg}$ and $96.41 \mathrm{mg}$ of AA and calcium, respectively. The increasing of AA was higher than GA, around 14 times, because of the difference in molecular structure (Figure 6) and water solubility capacity $(\mathrm{AA}=33.0 \mathrm{~g} / 100 \mathrm{ml}$ and $\mathrm{GA}=1.19 \mathrm{~g} / 100 \mathrm{ml}$ at $\left.20^{\circ} \mathrm{C}\right)$.

Sucrose content had slightly increased after PVOD without adding substances. However, the increasing sugar content was also slightly reduced by adding certain components in the solution as observed at the PVOD-SU+GA+AA+CAL sample. The diffusion efficiency of the added compounds into the food was supported by a sufficient content of SG in PVOD. Besides, the opening of intercellular space by acids in a medium was also considered in promoting diffusion that depended on molecular size of the added compounds. Hironaka et al. (2011) found that potato immersed in AA solution could significantly increase the content of AA in infused samples. However, the system with calcium ion showed a different result. The delaying increase in large molecules like sugar in fruit and vegetable samples with a calciumpectate solution, which resulted in reduction of tissue permeability (Jesus Junqueira et al., 2018). Previously, Emam-Djomeh et al. (2001) found that agar gel treated in sucrose solution had higher effective diffusion coefficients of sucrose than when treated with sucrose/ salt solutions, and a decrease in the effective diffusion coefficient of sucrose was observed as the salt concentration was increased. The flow of solutes occurred due to the concentration gradient between the solution and agar. Rózek et al.(2007) reported that MFC immersed in different solutions, such as sucrose, sodium chloride, sucrose combined sodium chloride and glycerol, would display significant differences in mass transfer. The molecular weight of solutes was considered as a factor that affected mass transfer phenomenon. 

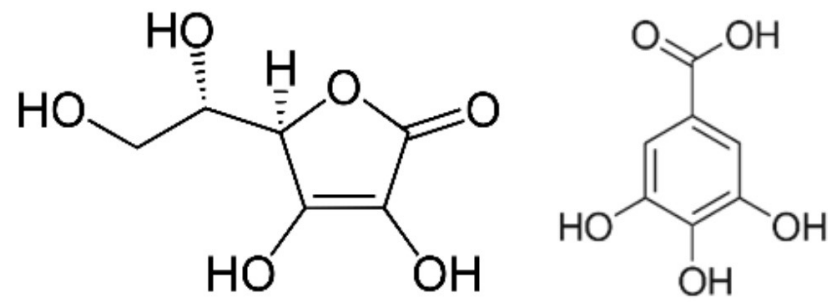

Figure 6: The different molecular structure of ascorbic acid (left) and gallic acid (right)

Table 5: Ascorbic acid, gallic acid, sucrose and calcium content in model food cubes

\begin{tabular}{lllll}
\hline \multicolumn{1}{c}{ Samples } & \multicolumn{1}{c}{$\begin{array}{c}\text { AA } \\
\text { (mg/100g sample) }\end{array}$} & $\begin{array}{c}\text { GA } \\
\text { (mg/g sample) }\end{array}$ & $\begin{array}{c}\text { SU } \\
\text { (g/100 g sample) }\end{array}$ & $\begin{array}{c}\text { CAL } \\
\text { (mg/ 100 g sample) }\end{array}$ \\
\hline Untreated & ND & ND & $11.10 \pm 0.01^{\mathrm{a}}$ & $\mathrm{ND}$ \\
PVOD-SU & ND & ND & $12.21 \pm 0.06^{\mathrm{c}}$ & $\mathrm{ND}$ \\
PVOD-SU+GA+AA+CAL & $953.18 \pm 1.65$ & $661.60 \pm 2.05$ & $11.88 \pm 0.02^{\mathrm{b}}$ & $96.41 \pm 0.21$ \\
\hline
\end{tabular}

$\mathrm{PVOD}=$ Pulsed vacuum osmotic dehydration, $\mathrm{GA}=$ Gallic acid, $\mathrm{AA}=$ Ascorbic acid, $\mathrm{SU}=$ sucrose, $\mathrm{CAL}=\mathrm{Calcium}$ lactate, $\mathrm{ND}=$ not detected, Values are means $\pm \mathrm{SD}$ of triplicate experiment, Values with the different letters (a-e) along the same columns are significantly different $(\mathrm{P}<0.05)$.

\section{Conclusion}

Concentration was the most influential factor in PVOD, followed by bulk density and time. The interaction effect between concentration, bulk density and time on change of mass transfer was shown when the experiment was conducted with a high concentration level. The amount of water removal from a model food is relatively low because of its water absorption property, while SG was significantly high. This is useful for the compound enrichment into the sample. In this study, a response surface methodology was effective, verified and proven to be reproducible, particularly SG and TSS. The quadratic model was appropriate in describing mass transfer. Optimum solution characteristics obtained by numerical optimization focusing on low concentration application, but with a sufficient SG in the sample were $32.58 \% \mathrm{w} / \mathrm{w}$ sucrose concentration, $0.8 \mathrm{~g} / \mathrm{ml}$ bulk density and $14.34 \mathrm{~min}$ of vacuum impregnation time. These optimum conditions provided satisfactory contents of AA, GA and calcium in MFC, which the products had low increasing sucrose content. These results could be applied to the development of new innovative products that might provide the desired compound level and functionality according to consumer requirements.

\section{Acknowledgements}

The authors like to thank Mahasarakham University, Thailand, for financial support.

\section{References}

Alam, M. S., Amarjit, S. \& Sawhney, B. K. (2010). Response surface optimization of osmotic dehydration process for aonla slices. Food Science and Technology, 47, 47-54. https://doi.org/10.1007/s13197-0100014-4

An, K., Tang, D., Wu, J., Fu, M., Wen, Jing., Xiao, G., \& Xucorresponding, Y. (2019). Comparison of pulsed vacuum and ultrasound osmotic dehydration on drying of Chinese ginger (Zingiber officinale Roscoe): Drying characteristics, antioxidant capacity, and volatile profiles. Food Science \& Nutrition, 7(8), 2537-2545. http://doi: $10.1002 /$ fsn3.110 
AOAC. (2000). The Association of Official Agricultural Chemistys, $17^{\text {th }}$ ed. Association of Official Analytical Chemists, Washington, DC, USA.

Aydogdu, A., Sumnu, G., \& Sahin, S. (2015). Effects of microwave-infrared combination drying on quality of eggplants. Food and Bioprocess Technology, 8(6), 1198-1210. https://doi.org/10.1007/s11947-015-1484-1

Betoret, E., Sentandreu, E., Betoret, N., Codoñer-Franch, P., Valls-Bellés, V., \& Fito, P. (2012). Technological development and functional properties of an apple snack rich in flavonoid from mandarin juice. Innovative Food Science and Emerging Technologies, 16, 298-304. https://doi. org/10.1016/j.ifset.2012.07.003

Dermesonlouoglou, E. K., Giannakourou , M. \& Taoukis P. S. (2016). Kinetic study of the effect of the osmotic dehydration pretreatment with alternative osmotic solutes to the shelf life of frozen strawberry. Food and Bioproducts Processing, 99,212-221,https:// doi.org/10.1016/j.fbp.2016.05.006.

Dermesonlouoglou, E. K., Zachariou, I., Andreou, V., \& Taoukis P.S. (2016). Effect of pulsed electric fields on mass transfer and quality of osmotically dehydrated kiwifruit. Food and Bioproducts Processing, 100, 535-544. https://doi.org/10.1016/j. fbp.2016.08.009.

Chottamom, P., Kongmanee, R., Manklang, C., \& Soponronnarit, S. (2012). Effect of Osmotic Treatment on Drying Kinetics and Antioxidant Properties of Dried Mulberry, Drying Technology, 30(1), 80-87. https:// doi: $10.1080 / 07373937.2011 .625461$

Chottanom, P., Pranin, T., Shopka, K., Nasinsorn, N. \& Itsaranuwat, P. (2015). Pulsed Vacuum Osmotic Dehydration of Cherry Tomatoes: Impact on Physicochemical Properties and Probiotics Entrapment. Walailak Journal of Science and Technology, 13(3), 193204. https://doi:10.14456/WJST.2016.19,

Corrêa, J. L. G., Pereira, M. L., Vieira, S. G., \& Hubinger, D., M. (2010). Mass transfer kinetics of pulsed vacuum osmotic dehydration of guavas. Food Engineering, 96(4), 498-504. https://doi.org/10.1016/j. jfoodeng.2009.08.032.

Corzo, O., Bracho, N., Rodríguez, J., \& González, M. (2007). Predicting the moisture and salt contents of sardine sheets during vacuum pulse osmotic dehydration. Food Engineering, 80(3), 781-790. https:// doi.org/10.1016/j.jfoodeng.2006.07.007.

Emam-Djomeh, Z., Djelveh, G., \& Gros, J.B. (2001).Osmotic dehydration of foods in a multicomponent solution part I. lowering of solute uptake in Agar Gels: diffusion considerations. LWT - Food Science and Technology, 34(5), 312-318. https://doi. org/10.1006/fstl.2001.0776.

Fermin, W. J., \& Corzo, O. (2005). Optimization of vacuum pulse osmotic dehydration of cantaloupe using response surface methodology. Food Process and Preservation, 29(1), 20-32. https://doi. org/10.1111/j.1745-4549.2005.00010.x

Fito, P., Chiralt, A., Barat, J.M., Andres, A., Martinez-Monzo, J., \& Martinez-Navarrete, N. (2001). Vacuum impregnation for development of new dehydrated products. Food Engineering, 49, 297-302. https://doi. org/10.1016/S0260-8774(00)00226-0

Giraldo, G., Talens, P., Fito, P. \& Chiralt, A. (2003). Influence of sucrose solution Concentration on kinetics and yield during osmotic dehydration of mango. Food Engineering, 58, 33-43. https://doi. org/10.1016/S0260-8774(02)00331-X.

Hironaka, K. , Kikuchi, M., Koaze, H. , Sato, T., Kojima, M., Yamamoto, K., Yasuda, K., Mori, M., \& S. Tsuda. (2011). Ascorbic acid enrichment of whole potato tuber by vacuum-impregnation. Food Chemistry, 127(3),1114-1118. https://doi. org/10.1016/j.foodchem.2011.01.111.

Ito, A. P., Tonon, R. V. Park, K. J., \& Hubinger, M. D. (2007). Influence of process conditions on the mass transfer 
kinetics of pulsed vacuum osmotically dehydrated mango slices. Drying Technology, 25(11), 1769-1777. https://doi. org/10.1080/07373930701593263

Jacob, J. K., \& Paliyath, G. (2012). Infusion of fruits with nutraceuticals and health regulatory components for enhanced functionality. Food Research International, 45, 93-102. https://doi.org/10.1016/j. foodres.2011.10.017.

Jalaee, F., Fazeli, A., Fatemian, H., \& Tavakolipour, H. (2011). Mass transfer coefficient and the characteristics of coated apples in osmotic dehydrating. Food and Bioproducts Processing, 89(4), 367-364. https://doi.org/10.1016/j.fbp.2010.09.012.

Jesus Junqueira, J. R., Corrêa, J. F. L. G., de Mendonça, K. S., de Mello Júnior, R. E,. \& de Souza, A.U. (2018). Vacuum Osmotic Dehydration of Beetroot, Carrot and Eggplant Slices: Effect of Vacuum Pressure on the Quality Parameters. Food and Bioprocess Technology, 11, 1863-1875. https://doi.org/10.1007/s11947-018-21479.

Loypimai, P., Moongngarm, A., \& Chottanom, P. (2016). Phytochemicals and antioxidant capacity of natural food colorant prepared from black waxy rice bran. Food Bioscience, 15, 34-41. https://doi.org/10.1016/j. fbio.2016.04.003.

Lech, K., Michalska, A., Wojdyło, A., Nowickab, P., \& Figiel, A. (2018). The influence of physical properties of selected plant materials on the process of osmotic dehydration. LWT - Food Science and Technology, 91, 588-594. https://doi.org/10. 1016/j.lwt.2018.02.012.

Liu, F., Shu-Fang F., Xiu-Fang B., Fang C., Xiao-Jun L., Xiao-Song H., \& Ji-Hong W. (2013). Physico-chemical and antioxidant properties of four mango (Mangifera indica L.) cultivars in China. Food Chemistry, 138(1), 396-405. https://doi.org/10.1016/j. foodchem.2012.09.111.
Moraga, M. J., Moraga, G., Fito, P. J., \& Martínez-Navarrete, N. (2009). Effect of vacuum impregnation with calcium lactate on the osmotic dehydration kinetics and quality of osmodehydrated grapefruit. Food Engineering, 90, 372-379. https://doi. org/10.1016/j.jfoodeng.2008.07.007.

Mujica-Paz, H., Valdez-Fragoso, A., LopezMalo, A., Palou, E., \& Welti-Chanes, J. (2003). Impregnation and osmotic dehydration of some fruits: effect of the vacuum pressure and syrup concentration. Food Engineering, 57, 305-314. https://doi. org/10.1016/S0260-8774(02)00344-8.

Nieto, A. B., Salvatori, D. M., Castro, M. A., \& Alzamora, S. M. (2004). Structural changes in apple tissue during glucose and sucrose osmotic dehydration: Shrinkage, porosity, density and microscopic features. Food Engineering, 61(2), 269-278. https://doi. org/10.1016/S0260-8774(03)00108-0

Nuñez-Mancilla, Y., Perez-Won, M., VegaGálvez, A., Arias, V., Tabilo-Munizaga, G., Briones-Labarca, V.,Lemus-Mondaca, R., \& Scala, k.D. (2011). Modeling mass transfer during osmotic dehydration of strawberries under high hydrostatic pressure conditions. Innovative Food Science \& Emerging Technologies, 12(3), 338-343. https://doi. org/10.1016/j.ifset.2011.03.005.

Nuñez-Mancilla, Y., Perez-Won, M., Uribe,E., Vega-Gálvez, A., \& Scala, K.D. (2013). Osmotic dehydration under high hydrostatic pressure: Effects on antioxidant activity, total phenolics compounds, vitamin $\mathrm{C}$ and colour of strawberry (Fragaria vesca). LWT - Food Science and Technology, 52(2),151-156. https://doi.org/10.1016/j. lwt.2012.02.027.

Panarese, V., Dejmek, P., Rocculi, P., \& Galindo, F. G . (2013). Microscopic studies providing insight into the mechanisms of mass transfer in vacuum impregnation. Innovative Food Science and Emerging Technologies, 18, 169-176. https://doi.org/10.1016/j.ifset.2013. 01.008 . 
Parniakov, O., Bals, O., Lebovka, N., \& Vorobiev, E. (2016). Effects of pulsed electric fields assisted osmotic dehydration on freezingthawing and texture of apple tissue. Journal of Food Engineering, 183, 32-38. https:// doi.org/10.1016/j.jfoodeng.2016.03.013

Phisut, N. (2012). Factors affecting mass transfer during osmotic dehydration of fruits. International Food Research Journal, 19(1), 7-18. http://agris.upm.edu.my:8080/ dspace/handle/0/12326

Rózek, A. Achaerandio, I. Almajano, M.P. GÜell, C. López, F. \& Ferrando, M. (2007). Solid foodstuff supplemented with phenolics from grape: antioxidant properties and correlation with phenolic profiles. Journal of Agricultural and Food Chemistry, 55 (13), 5147-5155. https://doi.org/10.1016/j. jfoodeng.2006.07.007.

Rózek, A., Achaerandio, I., Almajano, M.P ., GÜell, C., López, F., \& Ferrando, M. Use of commercial grape phenolic extracts to supplement solid foodstuff. LWT - Food Science and Technology, 43, 4, 623-631. https://doi.org/10.1016/j.lwt.2009.11.002.
Shi, J., \& Xue Jun, S. (2009). Application and development of osmotic dehydration technology in food processing. In C. Ratti (Ed.). Advances in food dehydration (pp. 187-208). LLC, Taylor \& Francis Group.

Schulze, B., Hubbermann, E. M., \& Schwarz, K. (2014). Stability of quercetin derivatives in vacuum impregnated apple slices after drying (microwave vacuum drying, air drying, freeze drying) and storage. LWT - Food Science and Technology, 57(1), 426-433. https://doi.org/10.1016/j. lwt.2013.11.021.

Suresh, K., \& Devi, P.(2011). Optimization of some process variables in mass transfer kinetics of osmotic dehydration of pineapple slices. International Food Research, 18, 221-238. http://www.ifrj.upm.edu.my/ volume-18-2011.html.

Yadav, B. S., Yadav, R.,B., \& Jatain, M. (2012). Optimization of osmotic dehydration conditions of peach slices in sucrose solution using response surface methodology. Food Science and Technology, 49, 547555.https://doi.org/10.1007/s13197-0110298-z. 